DOI: 10.1515/ausp-2017-0023

\title{
Fabrizio Macagno, Douglas Walton Interpreting Straw Man Argumentation. The Pragmatics of Quotation and Reporting Cham: Springer Publishing House, 2017
}

\author{
Review by \\ Zsuzsanna AJTONY \\ Sapientia Hungarian University of Transylvania (Miercurea Ciuc, Romania) \\ Department of Humanities \\ ajtonyzsuzsa@uni.sapientia.ro
}

The interdisciplinary field of pragmatics and argumentation proves to be a very thought-provoking area. One of the latest achievements of the domain is a book authored by two distinguished scholars in language philosophy, pragmatics, and argumentation theory, Fabrizio Macagno and Douglas Walton, and is entitled Interpreting Straw Man Argumentation. The Pragmatics of Quotation and Reporting. The volume addresses one of the most current topics of our age, the issue of applying a special kind of strategy in political arguments.

In recent political debates, it is frequently very difficult to decide whether the opposing candidates' position is correctly interpreted and presented, or it is distorted and manipulated. Due to the fact that the latest US presidential debates were often characterized by "misquotations, attacks based on incorrect quotations, and accusations of misquotations" (Macagno-Walton 2017: xiii), the authors of the book propose to analyse these linguistic and argumentative issues, especially concentrating on a strategy called in the literature "the straw man fallacy", which best illustrates the wilful alteration of one's opponent's words or communicative intentions. The "straw man fallacy" was originally referred to as the Aristotelian sophism, a clever but false argument called ignoratio elenchi, i.e. ignorance of what must be proved against one's adversary, proving something other than what is at issue. As the authors define it, "the straw man in the attack on (or refutation of) a view that the speaker attributes to his adversary, but that does not correspond to the adversary's actual position, but rather to a distorted (misrepresented) version of it" (Macagno \& Walton 2017: xiii). Attacking a view that only resembles the one advocated by the adversary presupposes several 
strategies of distortion and misrepresentation (Walton 2003: 42-44). These strategies are investigated and mapped in the book.

The authors propose to provide instruments from pragmatics and argumentation theory to assess whether a quotation is correct and whether the original speaker has been correctly interpreted. The book also investigates how quotations can be distorted and used for manipulating the original speaker's commitments. Finally, it also aims at describing the dialectical and rhetorical strategies based on misquotations (in doing so, the argumentation theory hallmarked by van Eemeren and his research group is heavily referred to). They propose to show how these strategies can be analysed and diagnosed, offering the misquoted party tools for countering and rebutting the quoting person's move.

Due to the fact that semantic ambiguity frequently characterizes natural communication, the line between interpreting one's words correctly and purposely altering a speaker's commitment is often blurred. In several cases, speaker meaning is simply implied (not explicitly uttered), i.e. it is simply taken for granted. In order to properly infer (retrieve) what our interlocutor meant, the tacit dimension of communication needs to be taken into account, i.e. the implicit aspects of an utterance, the presuppositions related to it, and the assessment of the interpretation that can be considered acceptable. This is the process of pragmatic inference. It includes taking into account the purpose of the dialogue, the co-text (the linguistic environment in which an utterance is used within a discourse), the context (the entirety of circumstances that surround the production of language), and the mutual contextual beliefs (encyclopaedic facts and habits) that surround a dialogue. When doubts arise concerning the meaning of an utterance, interpretation becomes of utmost importance. Interpretation is a critical process in which the interpreter needs to find the meaning grounded on the most acceptable reasons, "arguments, evidence, and presumptions, supporting an interpretive conclusion that can be compared with the alternative ones" (Macagno \& Walton 2017: xvi).

The most evident areas in which quotations are crucial are communication, rhetoric, and public discourse. In order to prove their point, the authors use examples from famous speeches from American political life, speeches delivered by former and current presidents like Nixon, Obama, Bush, Clinton, and Trump, political debates but also defamation cases and legal discussions. They examine 63 examples of uses of quotations and misquotations and 20 legal cases through which they provide not only an analytical and normative framework but they also offer practical methods to apply this framework to real-life arguments.

The book is structured into five main chapters, each one containing several subchapters and ending with conclusions. The first chapter discusses the argumentative use and manipulation of quotations by referring to how the quoter uses the original act of the Original Speaker (OS) to pursue his own dialogical or communicative goal. 
The second chapter is entitled Communicative Intentions and Commitments, and it focuses on the problem of direct or indirect reporting of a point of view, pinpointing the fact that no reporting can be analysed by disregarding the context in which it appears and the intention of the speaker. Reports are related to the relevance of the quotation; they are always dependent on the purpose the quoter is pursuing in his/her discourse. In terms of argumentation theory, both quotations and reports can be approached according to whether they support or refute the interlocutor's viewpoint, i.e. they can be evaluated as pieces of evidence to be used as arguments for or against the opposing party's stance.

The third chapter focuses on the issue of Establishing Commitments between Ambiguity and Misquotation and examines quotations and misquotations from an argumentation perspective, clarifying the relation between quotations, interpretations, and commitments. This chapter also shows the existence of different kinds of ambiguity and how this ambiguity can create presuppositions to be properly identified by using the so-called Gricean implicature. The authors draw attention to the fact that "a potential ambiguity can be used as a strategy for manipulating commitments for holding the quoted party responsible for positions that he never advocated" (Macagno \& Walton 2017: xviii).

Chapter four turns to The Strategies of Misattribution of Commitments, investigating the argumentative mechanism that can be used for interpreting ambiguous or potentially ambiguous utterances. It is here that the different types of straw man are discussed. As mentioned above, the straw man is a weaker, distorted version of the original speaker's claim or argument, and, according to the authors, this can be carried out via meta-dialogical strategies (directly or indirectly attacking the original speaker) and dialogical strategies (rejecting the claim or argument of the OS by exclusion, rebuttal, or undermining).

Last but not least, chapter five, entitled Evaluating Relevance and Commitments in Rhetorical Straw Man, summarises the results obtained through the analyses carried out in the first four chapters and clarifies the interrelation between the various aspects of the fallacy of straw man. The final conclusion is that the straw man fallacy is a failure of relevance, thus arriving at a new definition of relevance (originally proposed by Sperber \& Wilson 1995 [1986]), this time appropriate for argumentation. In this sense, "relevance can be used as a criterion for assessing the reasonableness of an interpretation or report" (Macagno \& Walton 2017: xviii).

Through the use of numerous examples and very clear explanations, the book Interpreting Straw Man Argumentation. The Pragmatics of Quotation and Reporting is a useful resource book not only for specialists, scholars in the field of communication in general, and political communication in particular, in argumentation theory, rhetoric, and pragmatics but also for students and nonspecialists who would like to get an insight into the identification and repair of 
the defects of argumentation arising from the misquotation and misrepresentation of an arguer's position.

\section{References}

Macagno, Fabrizio-Douglas Walton. 2017. Interpreting Straw Man Argumentation. The Pragmatics of Quotation and Reporting. Cham: Springer International Publishing.

Sperber, Dan-Deirdre Wilson. 1995 [1986]. Relevance: Communication and Cognition. $2^{\text {nd }}$ edition. Oxford: Blackwell.

Walton, Douglas. 2003. Relevance in Argumentation. Amsterdam-Philadelphia: Routledge. 